\title{
Grain Evolution in Thermally Aged Cast and Hot Isostatic Pressed Inconel 625
}

\author{
E. Getto ${ }^{1}$, B. Tobie ${ }^{1}$, E. Bautista ${ }^{2}$, A. Bullens ${ }^{2}$, D.W. Gandy ${ }^{3}$, and J.P. Wharry ${ }^{2}$ \\ 1. Department of Mechanical Engineering, United States Naval Academy, Annapolis, MD, USA \\ 2. School of Nuclear Engineering, Purdue Engineering, West Lafayette, IN, USA \\ 3. Electric Power Research Institute, Charlotte, NC, USA
}

Inconel 625 is a nickel-based superalloy of critical interest to both civilian and defense nuclear reactor community due to its excellent high temperature properties including corrosion resistance as well as creep resistance, making it ideal for internal reactor components such as steam generator tubes [1]. Traditionally, Inconel 625 has been wrought or cast during the manufacturing process but recently, powder metallurgy and hot isostatic pressing (PM-HIP) has been considered as a low cost alternative to fabricate components near-net shape. Thus, an analysis of the microstructure is required to determine if PM-HIP is suitable for use in reactor applications.

Given the dependence of mechanical properties on the grain microstructure, a logical comparison method is the utilization of electron backscatter diffraction (EBSD). Prior to characterization, two sets of samples were obtained, one manufactured by casting and one PM-HIPed. These samples were subjected to thermal aging at either 400,600 or $800^{\circ} \mathrm{C}$ to either 100 or $1000 \mathrm{hr}$ to simulate the reactor environment. After aging, samples were polished with SiC followed by a vibratory polish with a 0.02 $\mu \mathrm{m}$ silica solution. Scanning electron microscopy (SEM) and EBSD imaging was performed at the Center for Material Characterization at the United States Naval Academy with a Tescan Mira SEM. All scans had a scan area of $500 \times 500 \mu \mathrm{m}$ with $\mathrm{e}^{-}$energy of $20 \mathrm{kV}$ and beam current of $8.4 \mathrm{nA}$.

A representative selection of the inverse pole figures are presented in Figure 1. The as-cast alloy is shown in Figure 1a and compared to the $100 \mathrm{hr}$ (b) and $1000 \mathrm{hr}$ (c) aging conditions performed at $400^{\circ} \mathrm{C}$. Likewise, the as-HIPed condition is compared from un-aged (d) to $100 \mathrm{hr}$ (e) and $1000 \mathrm{hr}$ (f). A high incidence of twinning, consistent with other Ni-base superalloys was observed. Qualitatively, there was an increase in grain diameter with thermal aging, especially apparent at $1000 \mathrm{hr}$. Furthermore, the PMHIP grains were consistently smaller in size, an indicator of higher strength. Figure 2 a plots the average grain area of the cast (blue circles) and PM-HIP (red triangles). The as received, non-aged results are plotted at nominal room temperature. PM-HIP had consistently smaller grains at nearly all aging conditions. Small increases in grain diameter were noted at all temperatures after 100 hours, although this was larger at $400^{\circ} \mathrm{C}$, which was unexpected. At the highest aging temperature $\left(800^{\circ} \mathrm{C}\right)$, the most grain growth was observed in the cast but not PM-HIP. Figure $2 \mathrm{~b}$ compares the 100 and $1000 \mathrm{hr}$ aging times for PM-HIP. The weak dependence on temperature observed in Figure 2a was consistent with results shown in Figure 2b. Finally, every aging temperature demonstrated increased grain growth at $1000 \mathrm{hr}$. The weak dependence on temperature may be explained by the low temperature: grain growth is expected at $0.5 \mathrm{~T} / \mathrm{T}_{\mathrm{m}}$ and thus only expected in temperatures in excess of $\sim 550^{\circ} \mathrm{C}$.

This study demonstrated the effect of aging temperature and time on the grain structure of cast and PMHIP Inconel. Preliminary results suggest that the smaller grain structure of the PM-HIP remained throughout all aging conditions and may indicate higher strength, but future work will include analysis of any phases precipitated out during the long aging processes relevant to reactor operations. 


\section{References:}

[1] V. Shankar, K. Bhanu Sankara Rao, K., \& S. Mannan. (2001). J. Nucl. Mater., 288 (2001) 222-232. [2] This work was conducted under award 15-8242 from the Nuclear Science User Facilities by the DOE Office of Nuclear Energy, under DOE Idaho Operations Office Contract DE-AC07-05ID14517. Dr. B. Baker is thanked for his many useful discussions and contributions to this work as well as Mr. Michael Spencer for assistance in sample preparation.

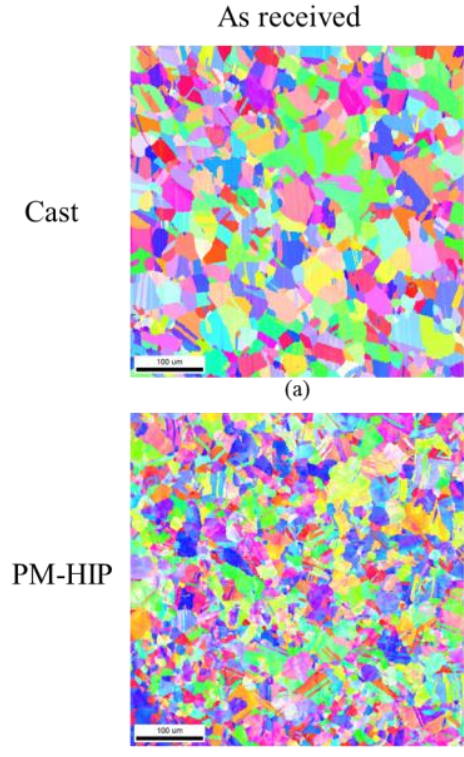

(d)

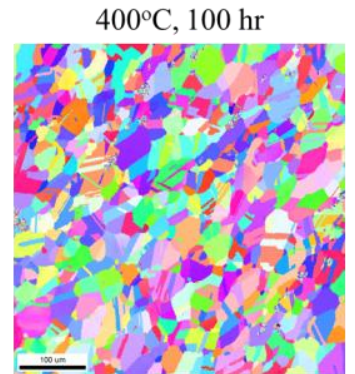

(b)

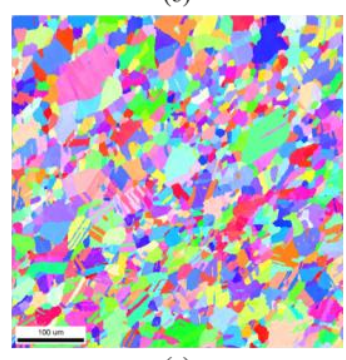

(e)

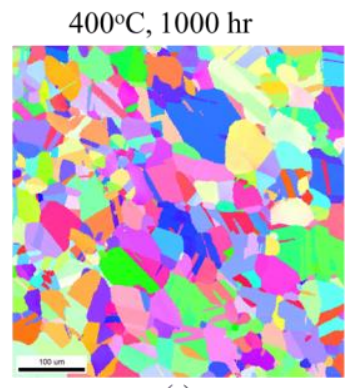

(c)

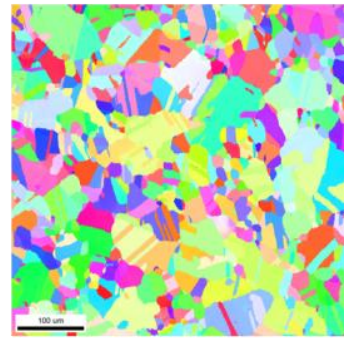

(f)

Figure 1. Inverse pole figures $(500 \mu \mathrm{m} \times 500 \mu \mathrm{m})$ of Inconel 625 manufactured by casting (a) or PMHIPing (b) aged at $400^{\circ} \mathrm{C}$ for $100 \mathrm{hr}(\mathrm{b}, \mathrm{e})$ or $1000 \mathrm{hr}(\mathrm{c}, \mathrm{f})$.

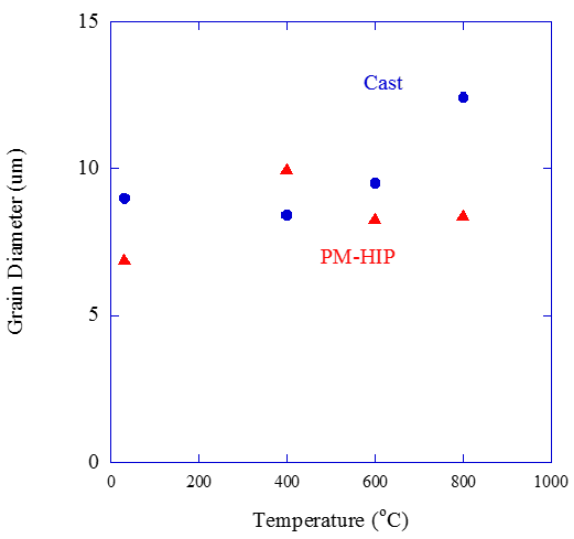

(a)

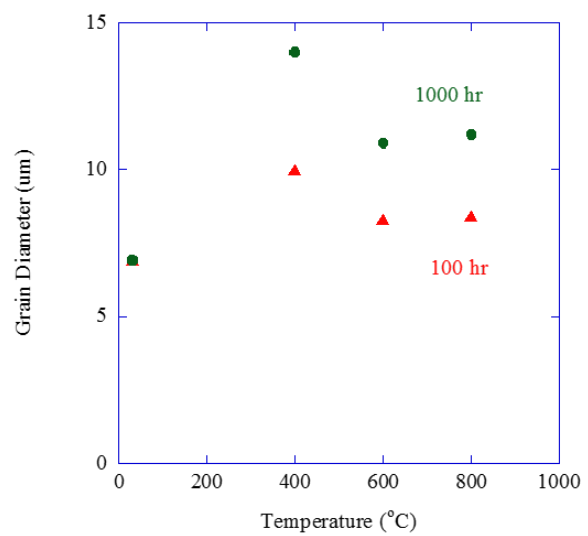

(b)

Figure 2. a) Comparison of grain area of Inconel 625 that has been cast (blue circles) or PMHIP (red triangles) with thermal aging from 400 to $800^{\circ} \mathrm{C}$ for $100 \mathrm{hr} \mathrm{b}$ ) Increase in average grain area of Inconel 625-PMHIP with thermal aging from 400 to $800^{\circ} \mathrm{C}$ for $100 \mathrm{hr}$ (blue circles) or $1000 \mathrm{hr}$ (red triangles). 